\title{
Management of fistulas in patients with Crohn's disease: Antibiotic to antibody
}

Pierre Paré MD FRCPC FACG

P Paré. Management of fistulas in patients with Crohn's disease: Antibiotic to antibody. Can J Gastroenterol 2001;15(11):751-756. Fistulas are common in patients with Crohn's disease and, when associated with inflammatory disease and established for several weeks, tend to be chronic. Perianal fistulas are the most frequent complication of, and are most often associated with, colonic disease. Perianal fistulas commonly require surgical resection and permanent ileostomy. Antibiotics, cyclosporine, methotrexate and thalidomide have been used in uncontrolled trials; only azathioprine, 6-mercaptopurine and infliximab have been assessed in double-blind, placebo controlled studies. Relapse of the fistula occurs with all drugs, unless treatment is continued long term. Each drug differs in its onset of action and long term tolerability. An approach to fistulizing disease in Crohn's disease is suggested.

Key Words: Crohn's disease; Fistula

\section{Traitement des fistules chez les patients atteints de la maladie de Crohn : des antibiotiques aux anticorps}

RÉSUMÉ : Les fistules sont fréquentes chez les patients atteints de la maladie de Crohn et, lorsqu'elles sont associées à un processus inflammatoire et qu'elles persistent durant plusieurs semaines, elles ont tendance à se chroniciser. Les fistules périanales constituent la complication la plus fréquente et elles sont, la plupart du temps, associées à une atteinte du côlon. Leur traitement exige généralement la résection chirurgicale et une iléostomie permanente. Les antibiotiques, la cyclosporine, le méthotrexate et la thalidomide ont fait l'objet d'essais non comparatifs; seuls l'azathioprine, la 6-mercaptopurine et l'infliximab ont été évalués dans des essais menés à double insu, contre placebo. On a observé des rechutes avec tous les médicaments, sauf en cas de traitement prolongé. Chaque médicament est différent quant à son mode d'action et à sa tolérabilité à long terme. L'auteur propose une approche à l'égard du traitement des fistules dans le contexte de la maladie de Crohn.
Cistulization is a common complication of Crohn's dis- ease. The clinical significance of a fistula results from its localization and symptomatic consequences. Fistulas can be internal or external. While fistulas between adjacent bowel loops are frequent and often not symptomatic, internal fistulas between distant sites (gastrocolic, rectovaginal, rec-

Division of Gastroenterology, Centre Hospitalier Affilie Universitaire de Quebec, Hôpital St-Sacrement, Laval University, Québec, Québec

Correspondence and reprints: Dr Pierre Paré, Centre Hospitalier Affilie Universitaire de Quebec - Hôpital St-Sacrement, 1050 Chemin Ste-Foy,

Québec, Québec G1S 4L8. Telephone 418-682-7646, fax 418-682-7855, e-mail pierre.pare@cha.quebec.qc.ca

Received for publication March 27, 2000. Accepted September 21, 2000 
tovesical) may cause severe complications (1). External fistulas are communications between the intestine and the skin; the most common sites of occurrence are the perineum and the abdominal wall. Because fistulas are usually associated with active inflammatory disease, they tend to be chronic. When fistulas are present for several weeks, spontaneous closure occurs uncommonly (2). In a placebo controlled trial (3), the rate of closure of chronic fistulas in patients not treated with an immunosuppressive drug was $6 \%$ over two years. Surgery itself has not changed the morbidity of fistulas much; improved parasurgical modalities, including parenteral nutrition, have been more beneficial in the general management of these patients $(2,4)$.

The majority of lesions observed in therapeutic clinical trials of patients with fistulizing Crohn's disease have been perianal and other enterocutaneous fistulas. Perianal fistulas are more often associated with colonic disease than with small bowel disease. One-third of patients with colonic Crohn's disease have perianal fistulas; these patients are more likely to follow a chronic continuous disease course than patients without fistulas. The probability that a patient will require surgical resection (permanent ileostomy) due to fistula disease is increased in those with perianal fistulas (52\% compared with $23 \%$ in those without perianal fistulas, at 20 years; relative risk 2.1) (5).

Various therapies for the management of Crohn's disease have been reported to be effective in both uncontrolled and controlled trials. However, the effects of commonly used drugs such as 5 -aminosalicylic acid, steroids and budesonide on fistulization have not specifically been reported. Also, recent clinical trials of novel therapies, such as $\mathrm{Rh}$ interleukin-10, Rh interleukin-11, intercellular adhesion molecule-1, antisense oligonucleotide and anti-integrin alpha-4, beta-7 monoclonal antibody, have not reported the outcomes of fistulas.

Most trials designed specifically to assess the closure of fistulas have been uncontrolled (antibiotics, cyclosporine, methotrexate and thalidomide); only two drugs - azathioprine (AZA) or 6-mercaptopurine (6-MP), and infliximab - have been evaluated in randomized, placebo controlled studies. Most of the trials have enrolled a small number of patients - usually patients who were refractory to other therapies and with enterocutaneous fistulas (perianal fistulas in the majority). End points have usually been defined (closure or improvement), although outcome criteria have not always been provided or have been variable among studies (improvement scale, time to response at onset or at a scheduled visit). Also, results have been reported differently, according to the number of fistulas or the number of patients with fistulas. Future studies should be standardized, for example by incorporating the perianal disease activity index (6) and the Present-Korelitz system (3).

\section{ANTIBIOTICS}

Metronidazole in a dose of $20 \mathrm{mg} / \mathrm{kg}$, or 1000 to $1500 \mathrm{mg} /$ day has been studied in three uncontrolled trials (7-9). Closure of fistulas occurred in 37\%, 38\% and 56\% of patients, and improvement occurred in $63 \%, 62 \%$ and $28 \%$ of the 18,26 and eight enrolled patients, respectively. Time to response varied from one to two weeks, to 9.1 weeks. After discontinuation of therapy, fistulas relapsed in $72 \%$ of 18 patients, but rapid healing was observed upon reintroduction of the drug (8).

In two studies, administration of ciprofloxacin alone (10) or with metronidazole (11) resulted in a closure rate of about 20\% - lower than the rate achieved with metronidazole alone - and improvement occurred in 50\% and $64 \%$ of the 10 and 14 enrolled patients, respectively.

\section{AZA AND 6-MP}

In a meta-analysis of five placebo controlled studies conducted between 1971 and 1980, closure or improvement of fistulas was observed in $54 \%$ of treated patients ( 22 of 41 ) and in $21 \%$ of patients taking placebo (six of 29) (odds ratio 4.44 [95\% CI 1.50 to 13.20]) (12). A duration of treatment of more than 17 weeks was the strongest determinant of response of the active disease to the drug. Present et al (3), in a placebo controlled study, reported closure of $31 \%$ (nine of 29) versus 6\% (one of 17) of fistulas and improvement of $29 \%$ (seven of 24 ) versus $18 \%$ (three of 17 ) of fistulas in patients treated with 6-MP versus placebo. Two subsequent uncontrolled studies in 1985 (13) and 1991 (14) reported closure rates of $37 \%$ and $23 \%$, and improvement rates of $27 \%$ and $40 \%$ in 41 and 35 patients, respectively. The mean time to response with AZA 2.0 to $2.5 \mathrm{mg} / \mathrm{kg}$ or with $6-\mathrm{MP} 1.5 \mathrm{mg} / \mathrm{kg}$ ranged from 3.1 to 4.5 months, with $20 \%$ of patients taking more than four months for improvement to be observed. Relapse occurred in all eight patients whose treatment was discontinued after closure of their fistulas (13). An uncontrolled study with an intravenous loading dose of AZA showed a closure rate of $54 \%$ (seven of 13), with a time to response of less than four weeks (15). However, a controlled trial of oral AZA with or without initial intravenous loading resulted in similar rates of complete response of active Crohn's disease after eight, 12 and 16 weeks (16). Whether this observation also applies to closure or improvement of fistulas is unknown but is probable.

\section{CYCLOSPORINE}

Oral administration of cyclosporine has not been shown to be effective in the healing and maintenance of closure of fistulas (17). Better results have been obtained with an initial high dose of cyclosporine given intravenously $(4 \mathrm{mg} / \mathrm{kg}$ ) followed by an oral dose of 6 to $8 \mathrm{mg} / \mathrm{kg}$. In three uncontrolled studies (18-20), closure or improvement of fistulas was observed in more than $80 \%$ of patients after only three to seven days. During oral maintenance therapy, healing of fistulas was maintained, but relapse was frequent after discontinuation of cyclosporine (five of seven patients) (20).

\section{METHOTREXATE}

In a retrospective review of 16 patients with fistulas, administration of methotrexate resulted in closure of $25 \%$ and 
improvement of $31 \%$ (21). However, relapse was frequent after discontinuation of therapy.

\section{INFLIXIMAB}

Infliximab, a humanized chimeric monoclonal antibody to tumour necrosis factor-alpha, was recently assessed in a randomized, double-blind, placebo controlled study involving 94 patients with fistulas (22). After a median response time of two weeks, fistulas closed in 46\% (29 of 63) and 13\% (four of 31) of infliximab-treated and placebo-treated patients, respectively; improvement was also noted in $16 \%$ (10 of 63 ) and $13 \%$ (four of 31 ), respectively. Two doses of infliximab ( 5 and $10 \mathrm{mg} / \mathrm{kg}$ ) were tested; the lower dose was associated with a higher response rate. There was a consistent treatment benefit regardless of concomitant therapy (eg, the presence or absence of therapy with AZA or 6-MP). However, the effect of treatment was not maintained; about $60 \%$ of patients with closed fistulas relapsed four months after the last infusion, and more than 90\% relapsed 12 months after the last infusion (23). Overall, the median duration of response was three months (22). Infliximab was administered at zero, two and six weeks for the treatment of fistulas. A recent study showed that patients who failed to respond to the second infusion were unlikely to respond to the third infusion, suggesting that the last dose is not necessary to achieve the same results (24).

\section{THALIDOMIDE}

Two recent uncontrolled studies $(25,26)$ involving patients with Crohn's disease suggested that only a few weeks' treatment with thalidomide may result in closure or improvement of fistulas; better outcomes were observed at doses between 100 and $300 \mathrm{mg} /$ day.

\section{ANECDOTAL CASE REPORTS}

Case reports have suggested a benefit of granulocyte colony-stimulating factor (27), oral tacrolimus (28) and clofazimine (29) in the treatment of fistulizing Crohn's disease .

\section{TOLERABILITY AND SAFETY OF DRUGS}

In general, all drugs can be used safely by physicians who have experience with specific therapeutic modalities. Nevertheless, adverse events are common with all drugs and may lead to withdrawal of therapy.

Metronidazole, when used for several months at high doses, has been associated with side effects in almost all patients; these side effects often appear before the beneficial effects. The most common side effects are paresthesias due to peripheral neuropathy (about $50 \%$ of patients), metallic taste and gastrointestinal symptoms; all side effects are usually reversible after discontinuation of the drug $(7,8)$. In one trial (8), six of 26 patients $(23 \%)$ withdrew from therapy because of adverse events. Although the side effects were dose related, an attempt to reduce the dose of metronidazole resulted in the exacerbation of the fistulizing disease (8). While evidence of mutagenecity and carcinogenecity has been reported in animal studies, a risk has not yet been defined in humans.

Side effects resulting from high doses of cyclosporine include headache $(50 \%)$, paresthesias (26\%), hypertrichosis $(13 \%)$, hypertension $(11 \%)$, tremor $(7 \%)$, renal insufficiency $(6 \%)$, opportunistic infection (3\%), gingival hyperplasia $(2 \%)$, seizures $(1 \%)$ and rarely anaphylaxis. The biggest issue that prevents the long term use of cyclosporine at high doses is the potential for permanent renal damage; infections and malignancy are other areas for concern (30).

In a trial using thalidomide 200 to $300 \mathrm{mg} /$ day, sedation was reported to some extent by all patients, often requiring a reduction in the dose. Overall, three of the 22 patients (14\%) discontinued the drug because of adverse events (25). The safety profile improved in a trial using a lower dose (50 to $100 \mathrm{mg} /$ day); the most common side effects were sedation $(58 \%)$, peripheral neuropathy $(42 \%)$, edema $(17 \%)$ and dermatitis $(8 \%)$, and were reported to be mild and mostly transient (26).

For patients with inflammatory bowel disease (IBD), the overall rate of side effects with long term 6-MP treatment was $15 \%$, including infections $(7 \%)$, pancreatitis $(3 \%)$, bone marrow depression (2\%), allergic reactions $(2 \%)$ and hepatitis $(0.3 \%)$ (30). In a meta-analysis, withdrawal of therapy because of adverse events was reported in 27 of 302 $(8.9 \%)$ patients treated with AZA or 6-MP, and in six of $353(1.7 \%)$ patients given placebo (12). The frequency of malignancy in patients treated over the long term with AZA or 6-MP for IBD has been reported to be $3 \%$ to $4 \%$ $(31,32)$. Although this rate may represent an increased risk compared with that of control populations, it is suggested that the risk is due to an increased incidence of malignancy, mostly lymphoma, in patients with IBD (33) .

In a trial using infliximab for the treatment of fistulas (22), side effects occurring more frequently with the active treatment than with the placebo were abscesses $(11 \%)$, upper respiratory tract infections (10\%) and fatigue (10\%). One of the $63(1.6 \%)$ patients treated with infliximab discontinued therapy because of pneumonia. Concerns about infliximab relate to the development of antidoublestranded DNA antibodies, human antichimeric antibodies and the risk of autoimmune diseases, acute infusion reactions, delayed hypersensitivity reactions and lymphoma (34-37). Remission of the inflammatory disease can be maintained over one year by retreatment with repeated infusions every eight weeks for 36 weeks; there is general tolerability to this prolonged treatment, but one case of lymphoma and one case of suspected drug-induced lupus were reported in a study involving 73 patients (36). There is a potential for serum sickness reactions and delayed hypersensitivity reactions when treatment is repeated after long intervals (two to four years) between infliximab doses (34). These adverse events were not seen in other studies of infliximab involving 475 patients with rheumatoid arthritis receiving two or more subsequent infusions over eight to 38 weeks at fixed four- to 12 -week intervals (35). A prelimi- 
TABLE 1

Drugs used for the treatment of fistulizing Crohn's disease

\begin{tabular}{lcccc}
\hline Drug & $\begin{array}{c}\text { Efficacy } \\
\text { (clos; global) }\end{array}$ & $\begin{array}{c}\text { Onset } \\
\text { of action }\end{array}$ & $\begin{array}{c}\text { Relapse } \\
\text { after D/C }\end{array}$ & $\begin{array}{c}\text { Long term } \\
\text { use } \\
\text { and safety }\end{array}$ \\
\hline $\begin{array}{c}\text { Antibiotics } \\
\text { (metro) }\end{array}$ & $\begin{array}{c}\text { Very high } \\
(44 \% ;>90 \%)\end{array}$ & Weeks & High & $\begin{array}{c}\text { Poorly } \\
\text { tolerated }\end{array}$ \\
$\begin{array}{c}\text { Cyclosporine } \\
\text { (high dose) }\end{array}$ & $\begin{array}{c}\text { High } \\
(28 \% ;>90 \%)\end{array}$ & Days & High & $\begin{array}{c}\text { Poorly } \\
\text { tolerated }\end{array}$ \\
$\begin{array}{c}\text { Thalidomine }(100 \\
\text { to 300 mg/day) }\end{array}$ & $\begin{array}{c}\text { Mod high } \\
(46 \% ;>70 \%)\end{array}$ & Weeks & Unknown & $\begin{array}{c}\text { Limited } \\
\text { tolerability }\end{array}$ \\
AZA/6-MP & $\begin{array}{l}\text { Mod high } \\
(30 \% ; 60 \%)\end{array}$ & Months & High & $\begin{array}{c}\text { Well } \\
\text { tolerated }\end{array}$ \\
& $\begin{array}{c}\text { Mod high } \\
\text { Infliximab }\end{array}$ & Weeks & High & $\begin{array}{c}\text { Probably } \\
\text { well tolerated }\end{array}$ \\
& $\begin{array}{l}\text { Mod high } \\
\text { MTX }\end{array}$ & - & High & $\begin{array}{c}\text { Limited } \\
\text { tolerability }\end{array}$ \\
\hline
\end{tabular}

AZA Azathioprine; Clos Closure; D/C Discontinuation; metro Metronidazole; Mod Moderately; 6-MP 6-Mercaptopurine; MTX Methotrexate

nary report on all patients prospectively observed up to three years after treatment in clinical trials suggested that the long term safety profile of infliximab is very good (38).

Toxicity reported to occur during low dose methotrexate treatment of autoimmune diseases such as psoriasis and rheumatoid arthritis includes diarrhea, mucositis, headache, central nervous system effects, hypersensitivity, pneumonitis, bone marrow suppression, hepatic fibrosis, or cirrhosis and lymphoma (30). In 94 patients with Crohn's disease treated with methotrexate $25 \mathrm{mg}$ administered weekly, $16(17 \%)$ withdrew from treatment because of adverse events, including asymptomatic elevation of serum aminotransferase levels in seven (7\%) and nausea in six (6\%) (39). However, a lower dose of methotrexate (15 mg/week) in a selected group of patients who most previously entered into remission after treatment with $25 \mathrm{mg} /$ week was associated with a good safety profile during 40 weeks of treatment (40). One of the major concerns about the long term use of low dose methotrexate in IBD patients is the potential for chronic liver disease. While a meta-analysis showed a 7\% overall risk of developing severe fibrosis or cirrhosis in patients with psoriasis (41), the risk is much lower in patients with rheumatoid arthritis, at approximately $1 \%$ (42). The actual risk of developing histologically advanced liver disease is not known in patients with IBD.

\section{DRUGS USED TO TREAT FISTULIZING CROHN'S DISEASE}

Overall (Table 1), metronidazole and cyclosporine have a high efficacy in closing or improving fistulas, with an onset of action of a few days to a few weeks. However, neither drug provides sustained healing of fistulas, and both are rather poorly tolerated. Thalidomide shows promise in
APPROACH TO FISTULIZING DISEASE

INFLIXIMAB

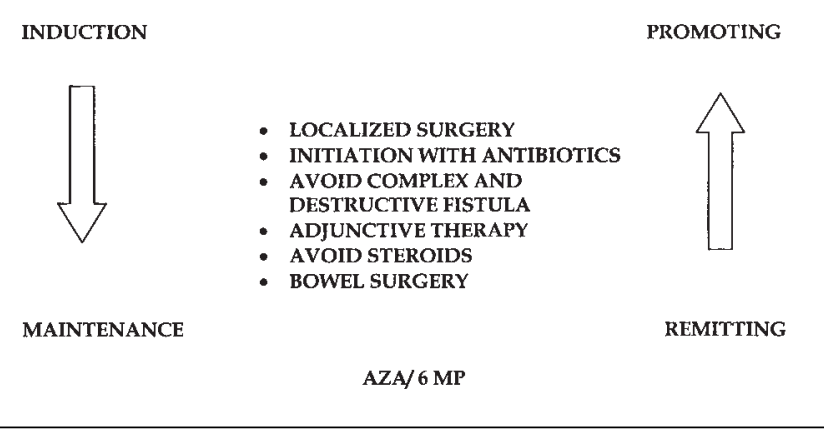

Figure 1) Approach to fistulizing disease. AZA Azathioprine; 6 MP 6-Mercaptopurine

inducing closure or improvement of fistulas within weeks, but the sustained response is not known, and the drug has a rather limited tolerability for chronic use. AZA or 6-MP, and infliximab are effective in the treatment of patients with fistulas and are well tolerated under their current use; the time to response is short (two weeks) with infliximab and prolonged (three months or more) with AZA and 6-MP. Fistulas frequently relapse after discontinuation of therapy with all drugs; AZA and 6-MP are the only drugs with an established long term safety profile (30). The long term safety profile of infliximab requires additional clinical investigation.

\section{MANAGEMENT OF IBD FISTULAS}

An ideal drug in the management of IBD fistula would treat the disease as well as the fistula; have a rapid onset of action; induce long term remission; be safe, easy to administrate and monitor; and be cost effective. No single drug can achieve all of these goals. The best management strategy is to induce early closure because fistulas lasting more than four to eight weeks are likely to become chronic (2). Surgery has an important role in the initial treatment of external fistulas. Localized and conservative surgical interventions should be used to drain an abscess and/or to place Seton sutures (43). Because localized sepsis is often involved in its formation, initiation of drug therapy appears to be appropriate with the use of metronidazole. If closure does not occur within the early weeks, the objective is to avoid the development of complex and destructive fistulas. Once a fistula is chronic, there is debate as to the choice of treatment (Figure 1). The first step is to induce closure of the fistula with a fast-acting drug such as infliximab and maintenance with a long term drug such as AZA or 6-MP, or to start a remitting therapy with AZA or 6-MP followed, if needed, by the use of a drug such as infliximab that promotes closure. The last scenario is what clinical trials have designed so far. Infliximab is the drug of choice in these two scenarios because of its rapid onset of action and high clo- 
sure rate, and because its effect may last two months or longer after treatment. Repeated courses of infliximab have not been shown to be effective in keeping fistulas closed; the safety of repeated treatment over a one-year period has been shown in patients with active Crohn's disease. Other fast-acting drugs do not usually maintain their effect long after discontinuation, and chronic or repeated administration of these drugs appears to be of limited long term tolerability. When a fistula fails to close, adjunctive therapy (antibiotics again, cyclosporine or tacrolimus, perhaps thalidomide) may be considered. At all times, if the active IBD persists, systemic corticosteroids should be avoided or used at the lowest dose. Indeed, steroid use has been associated with a poor prognosis for closure of enterovesical fistu-

\section{REFERENCES}

1. Givel JC, Hawker P, Allan R, et al. Entero-enteric fistula complicating Crohn's disease. J Clin Gastroenterol 1983;5:321-3.

2. Rose D, Yarborough MF, Canizaro PC, Lowry SF. One hundred and fourteen fistulas of the gastrointestinal tract treated with total parenteral nutrition. Surg Gynecol Obstet 1986;163:345-50.

3. Present DH, Korelitz BI, Wisch N, Glass JL, Sachar DB, Pasternack BS. N Engl J Med 1980;302:981-7.

4. Soeters PB, Ebeid AM, Fischer JE. Review of 404 patients with gastrointestinal fistulas. Impact of parenteral nutrition. Ann Surg 1979;190:189-202.

5. Lapidus A, Bernell O, Hellers G, Löfbert R. Clinical course of colorectal Crohn's disease: a 35-year follow-up study of 507 patients. Gastroenterology 1998;114:1151-60.

6. Irvine EJ. Usual therapy improves perianal Crohn's disease as measured by a new disease activity index. J Clin Gastroenterol 1995;20:27-32.

7. Jakobovits J, Schuster MM. Metronidazole therapy for Crohn's disease and associated fistulae. Am J Gastroenterol 1984;79:533-40.

8. Brandt LJ, Bernstein LH, Boley SJ, Frank MS. Metronidazole therapy for perineal Crohn's disease: a follow-up study. Gastroenterology 1982;83:383-7.

9. Bernstein LH, Frank MS, Brandt LJ, Boley SJ. Healing of perineal Crohn's disease with metronidazole. Gastroenterology 1980;79:357-65.

10. Turunen U, Färkkilä M, Valtonen V, Seppälä K. Long-term outcome of ciprofloxacin treatment in severe perianal or fistulous Crohn's disease. Gastroenterology 1993;104:A793. (Abst)

11. Solomon MJ, McLeod RS, O'Connor BI, Steinhart AH, Greenberg GR, Cohen Z. Combination ciprofloxacin and metronidazole in severe perianal Crohn's disease. Can J Gastroenterol 1993; 7:571-3.

12. Pearson DC, May GR, Fick GH, Sutherland LR. Azathioprine and 6-mercaptopurine in Crohn disease. A meta-analysis. Ann Intern Med 1995;122:132-42.

13. Korelitz BI, Present DH. Favorable effect of 6-mercaptopurine on fistulae of Crohn's disease. Dig Dis Sci 1985;30:58-64.

14. O'Brien JJ, Bayless TM, Bayless JA. Use of azathioprine or 6-mercaptopurine in the treatment of Crohn's disease. Gastroenterology 1991;101:39-46.

15. Sandborn WJ, van Os EC, Zins BJ, Tremaine WJ, Mays DC, Lipsky JJ. An intravenous loading dose of azathioprine decreases the time to response in patients with Crohn's disease. Gastroenterology 1995;109:1808-17.

16. Sandborn WJ, Tremaine WJ, Wolf DC, et al. Lack of effect of intravenous administration on time to respond to azathioprine for steroid-treated Crohn's disease. Gastroenterology 1999;117:527-35.

17. Sandborn WJ, Tremaine WJ. Cyclosporine treatment of inflammatory bowel disease. Mayo Clin Proc 1992;67:981-90.

18. Hanauer SB, Smith MB. Rapid closure of Crohn's disease fistulas with continuous intravenous cyclosporin A. Am J Gastroenterol 1993;88:646-9

19. Present DH, Lichtiger S. Efficacy of cyclosporine in treatment of fistula of Crohn's disease. Dig Dis Sci 1994;39:374-80. las in one study (44), and this finding may also apply to other types of fistulas. Although surgery might be considered as the last intervention, this is unfortunately not a definitive cure in patients with IBD.

Because the course of Crohn's disease is variable and largely unpredictable, an individualized approach to the treatment of fistulizing disease might be the preferred option based on the clinical situation, the patient's preference and expectations of quality of life issues, the physician's experience and local support for using a therapy and consequent cost-benefit compromise.

ACKNOWLEDGEMENT: The author thanks Mrs Rachel Simard for her expert secretarial assistance.
20. Egan LJ, Sandborn WJ, Tremaine WJ. Clinical outcome following treatment of refractory inflammatory and fistulizing Crohn's disease with intravenous cylosporine. Am J Gastroenterol 1998;93:442-8.

21. Mahadevan U, Marion JF, Present DH. The place for methotrexate in the treatment of refractory Crohn's disease. Gastroenterology 1997;112:A1031. (Abst)

22. Present DH, Rutgeerts PJ, Targan SR, et al. Infliximab for the treatment of fistulas in patients with Crohn's disease. N Engl J Med 1999;340:1398-405.

23. D'Haens GR, Aerden I, van Hogezand R, et al. Duration of response following cessation of infliximab therapy for active or fistulizing Crohn's disease. Gastroenterology 1999;116:G3029.

24. Toy LS, Marion JF, Scherl EJ, et al. Infliximab therapy for Crohn's disease fistulae: number of infusions required for response and time to relapse. Gastroenterology 2000;118:A569. (Abst)

25. Ehrenpreis Ed, Kane SV, Cohen LB, Cohen RD, Hanauer SB. Thalidomide therapy for patients with refractory Crohn's disease: an open-label trial. Gastroenterology 1999;117:1271-7.

26. Vasiliauskas EA, Kam LY, Abreu-Martin MT, et al. An open-label pilot study of low-dose thalidomide in chronically active, steroiddependent Crohn's disease. Gastroenterology 1999;117:1278-87.

27. Vaughan D, Drumm B. Treatment of fistulas with granulocyte colonystimulating factor in a patient with Crohn's disease. N Engl J Med 1999;340:239-40.

28. Sandbord WJ. Preliminary report on the use of oral tacrolimus (FK506) in the treatment of complicated proximal small bowel and fistulizing Crohn's disease. Am J Gastroenterol 1997;92:876-9.

29. Pinès $\mathrm{AE}$, Cosnes J, Carbonnel $\mathrm{F}$, et al. Le lamprène dans les localisations ano-périnéales de la maladie de Crohn. Une étude rétrospective. Ann Gastroenterol Hepatol (Paris) 1993;29:155-63.

30. Sandbord WJ. A review of immune modifier therapy for inflammatory bowel disease: azathioprine, 6-mercaptopurine, cyclosporine and methotrexate. Am J Gastroenterol 1996;91:423-33.

31. Present DH, Meltzer SJ, Krumholz MP, et al. 6-mercaptopurine in the management of inflammatory bowel disease: Short- and long-term toxicity. Ann Intern Med 1989;111:641-9.

32. Connell WR, Kamm MA, Dickson M, et al. Long-term neoplasia risk after azathioprine treatment in inflammatory bowel disease. Lancet 1994:343:1249-52.

33. Greenstein AJ, Mullin GE, Strauchen JA, et al. Lymphoma in inflammatory bowel disease. Cancer 1992;69:1119-23.

34. Hanauer SB, Rutgeerts PJ, D'Haens G, et al. Delayed hypersensitivity to infliximab (remicaide ${ }^{\circledR}$ ) re-infusion after a 2-4 year interval without treatment. Gastroenterology 1999;116:G3174. (Abst)

35. Schaible TF, Braakman T, Marsters P. Long-term safety of infliximab (anti-TNF $\alpha$ anti-body) in patients with rheumatoid arthritis: results of the attract trial. Gastroenterology 1999;116:G3528. (Abst)

36. Rutgeerts PJ, D'Haens G, Targan S, et al. Efficacy and safety of retreatment with anti-tumor necrosis factor antibody (infliximab) to maintain remission in Crohn's disease. Gastroenterology 1999;117:761-9. 
37. Bickston SJ, Lichtenstein GR, Arseaneau KO, Cohen RB, Cominelli F. The relationship between infliximab treatment and lymphoma in Crohn's disease. Gastroenterology 1999;117:1433-7.

38. Hanauer SB, Schaible TF, DeWoody KL, et al. Long-term follow up of patients treated with infliximab (anti-TNFA antibody) in clinical trials. Gastroenterology 2000;118:A566. (Abst)

39. Feagan BG, Rochon J, Fedorak RN, et al. Methotrexate for the treatment of Crohn's disease. N Engl J Med 1995;332:292-7.

40. Feagan BG, Fedorak RN, Irvine EJ, et al. A comparison of methotrexate with placebo for the maintenance of remission in Crohn's disease. N Engl J Med 2000;342:1627-32.
41. Whiting-O'Keefe QE, Fye KH, Sack KD. Methotrexate and histologic hepatic abnormalities: A meta-analysis. Am J Med 1991;90:711-6.

42. Kremer JM, Alarcon GS, Lightfoot RW Jr, et al. Methotrexate for rheumatoid arthritis. Suggested guidelines for monitoring liver toxicity. Arthritis Rheum 1994;37:316-28.

43. McCourtney JS, Finlay IG. Setons in the surgical management of fistula in ano. Br J Surg 1995;82:448-52.

44. Wheeler SC, Marion JF, Present DH. Medical therapy, not surgery, is the appropriate first line treatment for Crohn's enterovesical fistula. Gastroenterology 1998;114:G4555. (Abst) 


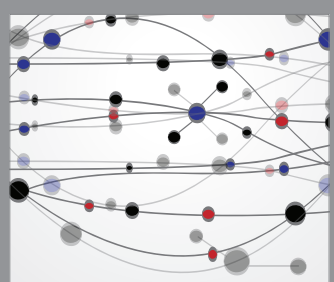

The Scientific World Journal
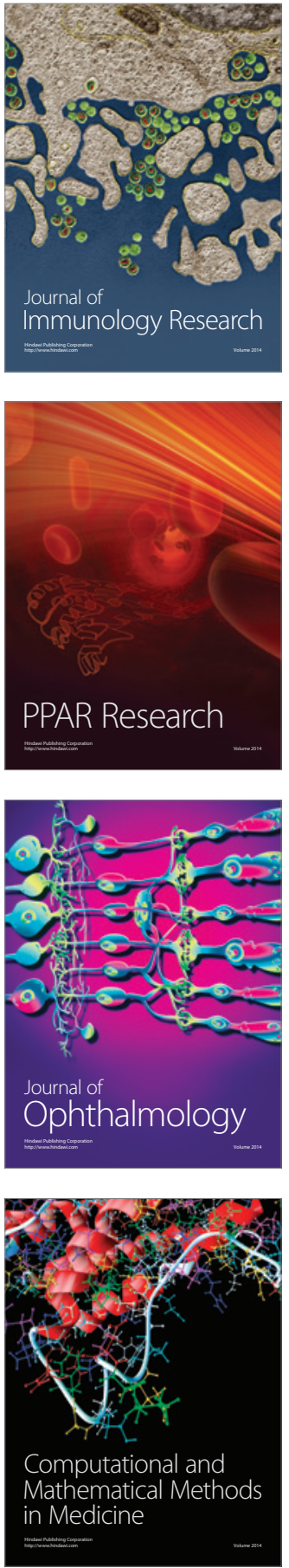

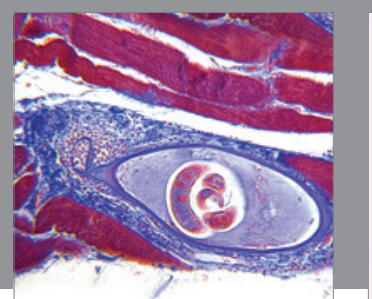

Gastroenterology Research and Practice

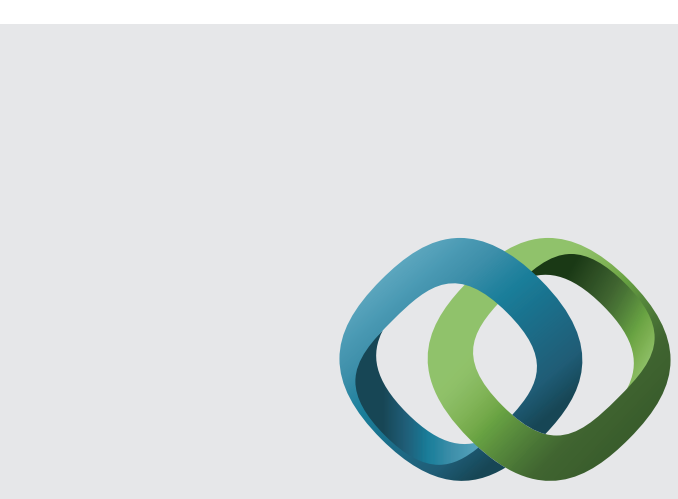

\section{Hindawi}

Submit your manuscripts at

http://www.hindawi.com
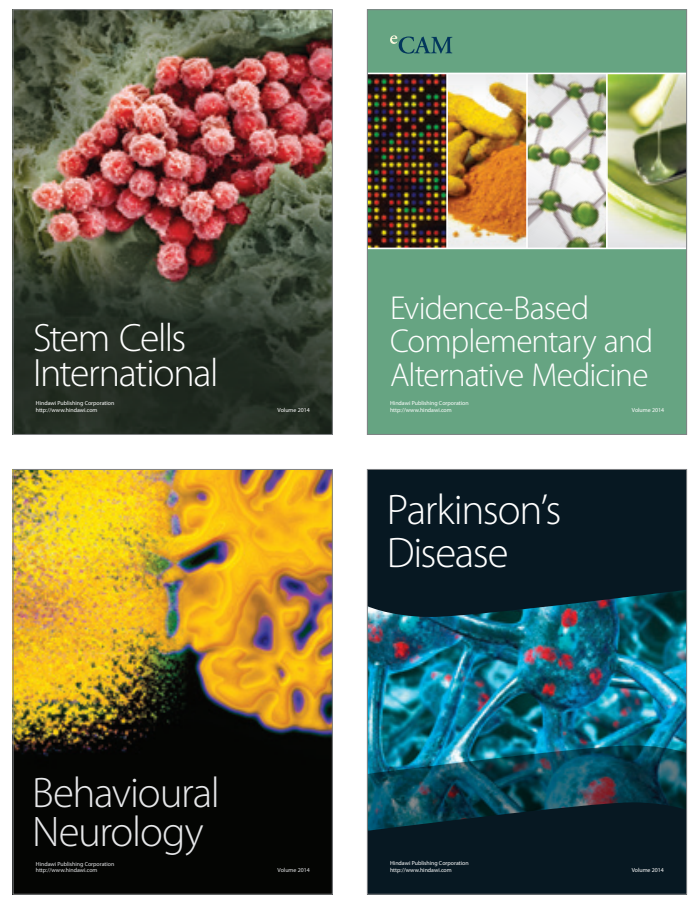
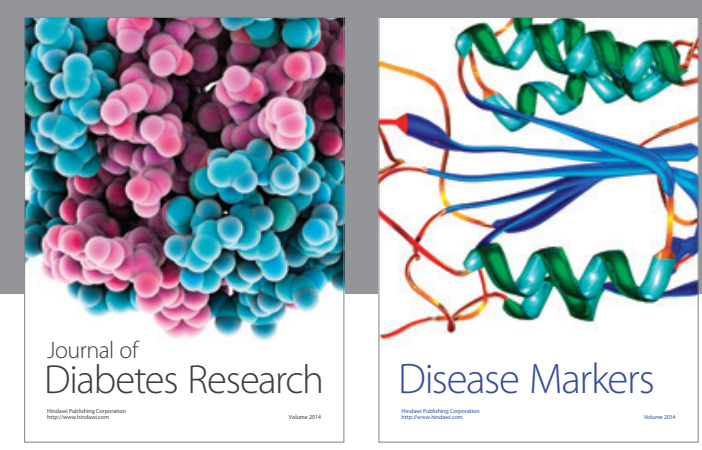

Disease Markers
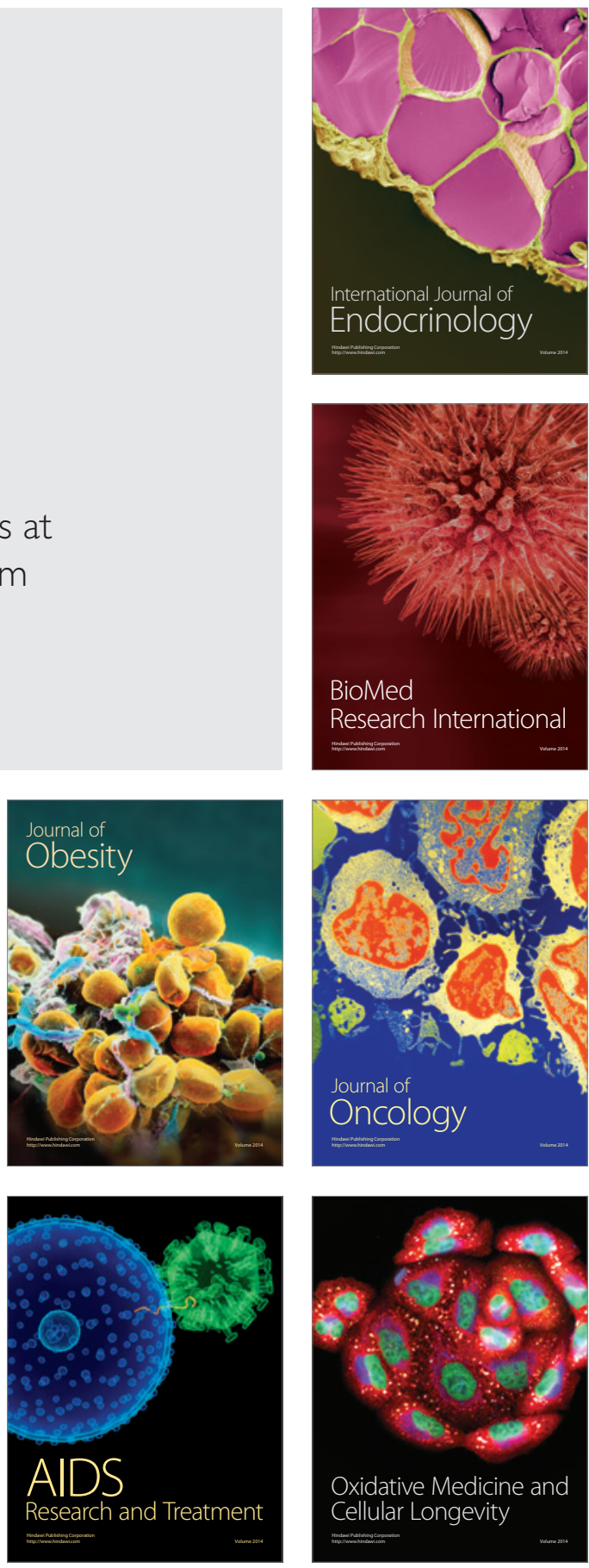